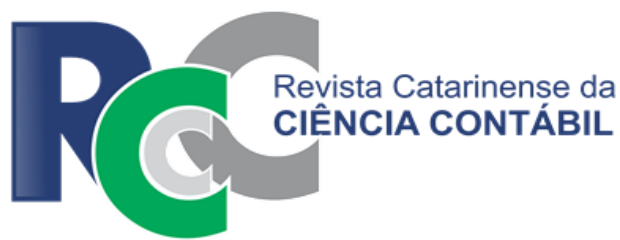

\title{
INTANGIBILIDADE E O VALOR DA EMPRESA: UMA ANÁLISE DO MERCADO ACIONÁRIO BRASILEIRO
}

\author{
INTANGIBILITY AND VALUE OF THE COMPANY: AN ANALYSIS OF THE \\ BRAZILIAN STOCK MARKET
}

\author{
HELLEN BOMFIM GOMES \\ Universidade Federal do Rio Grande do Norte. Endereço: Campus \\ Universitário, NEPSA II, Sala D9 | Lagoa Nova | 59078-970 | Natal/RN | \\ Brasil. \\ (1Dhttp://orcid.org/0000-0003-0529-2885 \\ hellenbomfim@hotmail.com
}

\section{TADEU JUNIOR DE CASTRO GONÇALVES}

Universidade Federal do Rio Grande do Norte. Endereco: Campus Universitário, NEPSA II, Sala D9 | Lagoa Nova | 59078-970 | Natal/RN | Brasil.

(D)http://orcid.org/0000-0002-2888-1773

tadeujunior@ufrn.edu.br

\author{
ADILSON DE LIMA TAVARES \\ Universidade Federal do Rio Grande do Norte. Endereco: Campus \\ Universitário, CCSA, Sala $6 \mid$ Lagoa Nova | 59078-970 | Natal/RN | Brasil. \\ (1) http://orcid.org/0000-0002-7800-9473 \\ adilson.tavares@uol.com.br
}

\section{RESUMO}

Visando preencher uma lacuna na literatura com relação aos impactos dos investimentos em ativos intangíveis no valor de mercado das companhias brasileiras, o presente estudo tem por objetivo investigar se existe associação entre o nível de intangibilidade e o valor de mercado das companhias abertas com ações negociadas na Brasil, Bolsa, Balcão (B3). A amostra compreende 158 companhias abertas não-financeiras listadas na B3, com dados disponíveis ao longo do período de 2010 a 2018. A coleta foi realizada através da base de dados Thomson Reuters Eikon. Os principais resultados evidenciam que, de fato, o nível de investimentos em ativos intangíveis das companhias apresenta uma relação positiva e estatisticamente significante com o valor de mercado. Assim, o investimento em ativos intangíveis desempenha, em especial, um papel de destaque entre os fatores específicos de desempenho da empresa, além de agirem como propulsores de vantagem competitiva. À luz da teoria do disclosure, infere-se que o fato de as empresas alcançarem uma maior valorização no mercado acionário, mediante o aumento no nível de investimentos realizados em ativos intangíveis, reporta à divulgação association-based, já que os efeitos da divulgação geram uma mudança agregada nas ações dos investidores, modificando o comportamento dos preços dos ativos e do volume de negociação. Ademais, os resultados apontam para consideráveis implicações para as empresas, gestores, acionistas e potenciais investidores. Na medida em que se compreende a influência positiva exercida pelo nível de investimento em ativos intangíveis no valor da empresa, pode-se inferir que benefícios fluirão dessa relação.

Palavras-chave: Ativos Intangíveis. Intangibilidade. Valor de Mercado. 


\begin{abstract}
This study aims to investigate the existence of an association between the level of intangibility and the market value of public companies with shares traded on the Brasil, Bolsa, Balcão (B3) to fill a gap in the literature regarding the impacts of investments in intangible assets on the market value of Brazilian companies. The sample comprises 158 non-financial publicly held companies listed on B3, with data available from 2010 to 2018. The collection was conducted using the Thomson Reuters Eikon database. The preliminary results show that the investment level in companies' intangible assets has a positive and statistically significant relationship with the market value. Thus, investment in intangible assets plays a specially prominent role among the company's specific performance factors and acts as drivers for a competitive advantage. In light of the disclosure theory, it appears that the fact that companies achieve greater appreciation in the stock market by increasing the level of investments made in intangible assets reports to an association-based disclosure since the effects of disclosure generate an aggregate change in investors' shares, changing the behavior of asset prices and trading volume. Furthermore, the results indicate considerable implications for companies, managers, shareholders, and potential investors. It can be inferred that benefits will flow from this relationship to the extent that the positive influence of the investment level in intangible assets on the company's value is understood.
\end{abstract}

Keywords: Intangible assets. Intangibility. Market value.

\title{
1 INTRODUÇÃO
}

Os contadores registram ativos no balanço de uma empresa que podem ser quantificados objetivamente. Mas a realidade da economia competitiva de mercado atual é que a propriedade de ativos tangíveis que são facilmente duplicados pelos concorrentes não é, por si só, suscetível de gerar retornos econômicos sustentados que excedam o custo de capital (Madden, 2017).

Com o avanço da globalização, se manter em um mercado progressivamente competitivo demanda cada vez mais a utilização de pesquisa e desenvolvimento, além da criação e utilização de recursos imperceptíveis fisicamente, mas que têm ganhado crescente relevância nos relatórios contábeis e consequentemente no mercado em geral. Assim, se discorre sobre os ativos intangíveis que, além da crescente importância reportada financeiramente, tiveram relevância para a academia nas últimas décadas, pois representam desafios e dilemas devido às informações complexas que eles contêm (Gu \& Wang, 2005; Higgins, 2013).

Sob essa perspectiva, os investimentos em inovação dão origem a um ciclo forte e determinante da riqueza das nações, configurando um cenário representado de um lado por universidades, institutos de pesquisa e empresas que são responsáveis por gerar conhecimentos e, de outro, por reguladores que desenvolvem políticas industriais de apoio e estímulo às atividades de inovação, assim como o sistema financeiro (Amaral, Iquipaza, Correia, Amaral, \& Vieira, 2014).

Nesse contexto, os ativos intangíveis constituem recursos valiosos para aumentar a competitividade e os lucros (Labidi \& Jean François, 2019). Desse modo, dentre as áreas de estudo dos intangíveis, cita-se a influência dos intangíveis no valor das empresas (Nichita, 2019), sobre a qual o presente estudo incrementa contribuições para a temática.

Higgins (2013) comenta que as empresas que possuem ativos intangíveis demandam atenção especial, pois nessas as informações sobre procedimentos de reconhecimento, mensuração, evidenciação e avaliação são muito mais complexas que das empresas em geral. Essas diferenças provocadas no valor da empresa podem estar diretamente relacionadas com a mensuração que o mercado faz da parte intangível das empresas, que inclui o capital intelectual, marcas, patentes, Pesquisa e Desenvolvimento (P\&D), entre outros (Amaral et al., 2014). Assim, a mensuração e divulgação de ativos intangíveis com precisão e rapidez são muito importantes, 
tendo em vista que ativos intangíveis podem apresentar um efeito positivo significativo no valor da empresa (Nagaraja \& Vinay, 2016).

Nessa linha, Dehning, Pfeiffer e Richardson (2006) discorrem que as informações sobre esses ativos são mais difíceis de interpretar, trazendo como consequência o aumento do risco sobre o investimento nas empresas. Desse modo, o custo de capital torna-se maior. Ainda, Gazzoni, Simões, Brandão e Souza (2019) comentam que os analistas financeiros devem observar tal aspecto em suas previsões de lucro.

A análise de intangíveis é uma parte crítica dos reportes corporativos, projetados para promover benefícios a todos os interessados. Os relatórios corporativos eficazes, em particular, exigem que esforços sérios sejam dedicados à tarefa de medir e gerenciar intangíveis com vistas a criar valor a longo prazo, melhorando, por sua vez, os julgamentos de plausibilidade do desempenho corporativo previsto e levando a melhores decisões de alocação de recursos refletindo tanto sobre seu histórico quanto sobre seu atual valor de mercado (Madden, 2017).

No Brasil, embora em um estágio ainda incipiente em relação ao que se pode observar na literatura internacional, verifica-se tendência de aumento das pesquisas envolvendo a temática dos ativos intangíveis, principalmente após a publicação da Lei $\mathrm{n}^{\circ} 11.638$, de 28 de dezembro de 2007 , pela obrigatoriedade do registro do grupo de Ativos Intangíveis, equiparando a legislação brasileira às práticas contábeis internacionais (Medrado, Cella, Pereira, \& Dantas, 2016).

Nesse sentido, o presente estudo tem por objetivo investigar se existe associação entre o nível de intangibilidade e o valor de mercado das companhias abertas com ações negociadas na Brasil, Bolsa, Balcão (B3).

Quanto à importância de se realizar um estudo nessa área, destacam-se dois motivos. Primeiro, teoricamente, ao realizar uma revisão da literatura, percebe-se que é uma temática em ascensão, ao passo que é possível identificar estudos como o de Medrado et al. (2016) que avaliaram, no campo do mercado de capitais brasileiro, a associação entre o nível de intangibilidade dos ativos e o valor de mercado das ações das empresas, utilizando informações trimestrais de 2008 a 2014 das empresas que compõem o índice IBrX 100 da BM\&FBovespa.

Medrado et al. (2016) justificam o período de análise (2008 a 2014) em decorrência do início da vigência da Lei $n^{\circ}$ 11.638/07 e do pronunciamento CPC 04. Quanto à decisão de estudar as empresas que compõem o índice IBrx 100, os autores advogam que o índice mede o retorno da carteira teórica composta por 100 ações selecionadas (números de negócios e volume financeiro) entre as mais negociadas na bolsa. Isto posto, o presente estudo se diferencia ao analisar empresas de diferentes setores da B3, fornecendo uma análise mais ampla, assim como analisa informações a partir de 2010 em decorrência da adoção obrigatória do International Financial Reporting Standard no Brasil.

Além de Medrado et al. (2016), menciona-se Gazzoni et al. (2019), que verificaram a influência dos intangíveis sobre a acurácia e a dispersão de previsões de lucros feita pelos analistas financeiros em uma amostra de empresas americanas não financeiras com ações negociadas na Nasdaq, compreendendo o período de 1995 a 2016, e Moura, Barbosa, Schio e Mazzioni (2020), que verificaram a influência dos ativos intangíveis no desempenho financeiro e no valor de mercado das companhias abertas familiares listadas na B3 no período de 2010 a 2017.

Diante do disposto, identificou-se um gap na literatura sobre ativos intangíveis que fornecesse uma análise do contexto nacional como um todo, dentro da perspectiva do nível de intangibilidade. Assim sendo, este estudo visa preencher a lacuna referente à associação do nível de intangibilidade e o valor de mercado das companhias abertas com ações negociadas na B3. Sucintamente, este estudo inova e contribui com os demais ao utilizar teoria (teoria da divulgação), método, amostra (158 companhias abertas não-financeiras listadas na B3) e período (2010-2018) diferentes.

O segundo motivo é que a necessidade de realização de novos estudos relativos a ativos intangíveis também se justifica por contribuir para aumentar a liquidez de ações, atrair investidores, aumentar a cobertura de analistas, reduzir a assimetria informacional e melhorar as 
previsões dos analistas em si (Gazzoni et al., 2019). Além disso, estudar o estado atual e as consequências e magnitudes futuras dos intangíveis em contabilidade e relatórios financeiros são necessários pelo motivo de criarem vantagens competitivas para as entidades (Nichita, 2019).

Conforme abordado por Andonova e Ruíz-Pava (2016), o enfoque em ativos intangíveis no contexto de um país emergente se torna relevante pelas seguintes razões: por um lado, os ativos intangíveis explicam a heterogeneidade do desempenho das empresas porque eles são difíceis de ser "imitados" pela concorrência e são protegidos por direitos de propriedade ou alto nível de especificidade; e, por outro lado, a fim de criar vantagem competitiva sustentável de longo prazo baseada em ativos intangíveis como know-how, marcas ou patentes, as empresas exigem mecanismos institucionais de aplicação que podem estar ausentes nos países emergentes.

Além desta seção, este estudo divide-se em mais quatro seções. Na seção 2, revisa-se a literatura de ativo intangível e se desenvolve a hipótese de pesquisa. Na seção 3, apresenta-se os procedimentos metodológicos. Na seção seguinte, os dados são descritos e analisados, e, por fim, apresentam-se as considerações finais e referências.

\section{REVISÃO DE LITERATURA E DESENVOLVIMENTO DA HIPÓTESE}

\subsection{Ativos intangíveis}

No atual ambiente global competitivo dos negócios, o potencial para obter retornos econômicos sustentados acima do custo de capital - que é especialmente valioso quando associado a taxas substanciais de reinvestimento - depende da capacidade da administração de identificar e realizar investimentos que possam contribuir significativamente para criação de valor da empresa de maneiras que são particularmente difíceis para os concorrentes replicarem (Madden, 2017). Esses investimentos são ativos intangíveis, parte integrante do processo de criação de valor, mas com uma dificuldade inerente associada à estimativa de seus valores patrimoniais e vida econômica.

$\mathrm{O}$ aumento de ativos intangíveis, como marcas, $\mathrm{P} \& \mathrm{D}$, patentes e outras formas de capital abstrato, tais quais plataformas digitais e fluxos de dados, levanta a necessidade de modificação de medidas e conceitos existentes sobre capital e acumulação, dentro da perspectiva de uma estrutura focada em mensurar por contadores, administrar por empresas e monitorar por estudiosos e reguladores (Bryan, Rafferty, \& Wigan, 2017). Isso se deve ao fato de o que costumava ser uma categoria de ativos residuais, em muitos casos, passou a superar os chamados ativos fixos ou tangíveis na lucratividade e avaliação de muitas empresas.

Segundo Lim, Macias e Moeller (2019), uma proporção substancial e crescente de ativos corporativos consiste em ativos intangíveis, e, apesar de sua considerável importância, os ativos intangíveis gerados internamente, que se mostram preponderantes nesse contexto, estão ausentes em grande parte dos balanços e outros relatórios corporativos. Dessa forma, o ambiente é propício para investigações acerca dos possíveis impactos que esses elementos contábeis podem conferir.

É sabido que os gestores, acionistas e potenciais investidores utilizam a contabilidade como referência em seu processo de tomada de decisão, em especial quando se refere à mensuração daquilo que lhes agrega valor. Esse parâmetro está relacionado a ativos que contêm a criação de valor e poder de crescimento para a empresa, mas que nem sempre assumem uma forma corpórea (tangibilidade), apresentando tão somente um compilado de informações, que têm a capacidade de obter alta deliberação no preço do produto da empresa, como também de gerar valorização e novos negócios (Amaral et al. 2014).

Seguindo esse ponto de vista, Loop, Scheffer e Lipfert (2004) ressaltam que, em decorrência desse movimento de substituição de ativos tangíveis por ativos intangíveis, investidores, instituições financeiras e reguladores são incentivados a dedicar atenção especial a esse tipo de investimento. Nessa perspectiva, Koller, Goedhart e Wessels (2005) explanam que, no procedimento de levantamento de informações para fins de avaliação de empresas, os ativos 
intangíveis requerem uma cuidadosa atenção, enfatizando que todos os ativos intangíveis devem ser levados em consideração para que o valor da empresa seja adequadamente determinado.

De acordo com Amaral et al. (2014), alguns dos principais fatores responsáveis pela percepção e consequente avaliação das empresas pelos mercados residem na existência de ativos intangíveis como marcas de expressão, capacidade tecnológica e capital intelectual. Os autores apontam que ainda há questões a serem resolvidas no que diz respeito à maneira como as entidades avaliam seus intangíveis e, por esse motivo, pesquisas são desenvolvidas sobre o assunto demonstrando o interesse por um tema em que ainda não se alcançou um consenso sobre a melhor abordagem para defini-lo e resolvê-lo adequadamente e os reais impactos que seus níveis de divulgação podem causar, ressaltando-se o gap existente entre o valor econômico e o valor contábil de uma entidade.

Fornecendo uma breve revisão das evidências empíricas existentes, André, Filip e Paugam (2017), utilizando uma amostra de 27.172 observações de companhias europeias para o período entre 2006 e 2015, reportam um nível médio (mediano) de intangíveis para um total de ativos de $16,7 \%(11,8 \%)$. Além disso, os autores também relatam uma relação de intangível/patrimônio líquido com uma média (mediana) de 47,4\% (30,0\%). No mesmo sentido, Mazzi, André, Dionysiou e Tsalavoutas (2017) se concentraram nos constituintes do S\&P Europe 350, mas para o período entre 2008 e 2011, e encontram níveis similares de ágio em relação ao valor contábil líquido.

De maneira complementar, Arrighetti, Landini e Lasagni (2014) afirmam, com base nos resultados encontrados em seu estudo, que há um aumento significativo na participação de ativos intangíveis no PIB dos EUA, Japão, Itália, Reino Unido, Finlândia e Holanda. Além disso, segundo os mesmos autores, essa tendência é acompanhada de evidências de que os ativos intangíveis contribuem positivamente para a lucratividade da empresa e dos setores de atuação, bem como para a avaliação de mercado.

Em termos de estrutura de capital, utilizando as recentes mudanças em regras contábeis que permitiu observar avaliações baseadas no mercado de ativos intangíveis, Lim et al. (2019) encontraram uma forte relação positiva entre ativos intangíveis identificáveis e alavancagem financeira. Segundo os resultados evidenciados, em geral, os ativos intangíveis identificáveis apoiam o financiamento, podendo suportar dívidas, e são fundamentais para gerar fluxos de caixa, tanto quanto os ativos tangíveis, em particular, nas empresas que carecem de ativos tangíveis em abundância.

Silveira, Schnorrenberger, Gasparetto e Lunkes (2017) analisaram as abordagens de avaliação dos ativos intangíveis por meio da literatura nacional e internacional. Assim, ao realizarem uma revisão de literatura em diferentes bases de pesquisa, os autores propuserem uma categorização dos estudos. Dentre as categorias destaca-se a de avaliação do retorno de ativos, quando não foram identificadas nenhuma abordagem. Ainda, os autores sugerem para pesquisas futuras as constatações na prática da utilização das abordagens de avaliação de ativos intangíveis, o que ressalta a importância da realização do presente estudo.

No contexto brasileiro, Kayo, Patrocínio e Martin (2009) analisaram a influência da intangibilidade sobre a criação de valor para as empresas adquirentes nos eventos de aquisição, incluindo $\mathrm{o}$ endividamento como moderador. Os resultados encontrados pelos autores evidenciaram que os intangíveis não teriam a capacidade, por si só, de criar valor nesse contexto. No entanto, quando as empresas intangível-intensivas apresentam alto nível de endividamento tendem a destruir valor em suas aquisições, ao passo que empresas intangível-intensivas que apresentem maior proporção de capital próprio podem criar valor nas aquisições, tendo em vista que possuem folga financeira para efetivar essas operações (Kayo et al., 2009).

Gu e Wang (2005) examinaram a relação entre as previsões de ganhos dos analistas e ativos intangíveis das empresas. Compreendendo o período de 1981 a 1998, os autores chegaram à conclusão de que a alta complexibilidade de informações de ativos intangíveis aumenta a 
dificuldade dos analistas e consequentemente o erro de previsão de analistas das companhias com uso intensivo de intangíveis.

Além da relação com os aspectos financeiros anteriormente discutidos, os ativos intangíveis também carregam uma carga informacional. Nesse sentido, Gazzoni et al. (2019) evidenciaram que os investimentos em $P \& D$ e ativos intangíveis contribuem para a previsibilidade do lucro pelos analistas, aumentando a acurácia e reduzindo a dispersão dessas estimativas no caso de empresas americanas não financeiras com ações negociadas na Nasdaq. Entretanto, os autores também reportam que o goodwill apresenta um efeito contrário: contribui para a redução da previsibilidade.

Moura et al. (2020) objetivaram verificar a influência dos ativos intangíveis no desempenho financeiro e no valor de mercado das companhias abertas familiares listadas na B3. Com dados retirados da Economática do período de 2010 a 2017 e realização de procedimentos quantitativos, os autores apontam que, em relação ao desempenho financeiro, os testes de médias evidenciaram que as diferenças no retorno sobre o ativo (ROA) e retorno sobre o patrimônio líquido (ROE) não são significativas entre as companhias familiares que possuíam maiores e menores investimentos em intangíveis e que para as empresas familiares os intangíveis influenciavam apenas para um maior valor de mercado.

De maneira geral, há um certo destaque em relação à relevância de investimentos em ativos intangíveis sobre o valor de mercado das companhias, reforçando a percepção de que o ambiente econômico das empresas com características baseadas em conhecimento e tecnologias mantém suas vantagens competitivas e aumenta o valor das ações (Medrado et al., 2016).

\subsection{Hipótese de pesquisa}

A divulgação seletiva de informações - na qual boas notícias são disponibilizadas visando afetar positivamente o retorno das ações ou no geral, obter algum benefício econômico, bem como a retenção de informações que poderiam resultar em um retorno negativo - é a base da teoria da divulgação (Verrecchia, 1983; Shalev, 2009). Em complemento, Shalev (2009) advoga que os gerentes que se comportam de acordo com esse raciocínio provavelmente divulgarão informações mais abrangentes sobre uma aquisição que eles esperam criar valor, assim como divulgarão menos informações sobre o que o que eles acreditam ser más notícias.

Sob a perspectiva da teoria da divulgação, Verrecchia (2001) categoriza o disclosure, quanto à taxonomia, em três grupos: (i) Association-based Disclosure, que trata dos efeitos da divulgação sobre a mudança agregada ou cumulativa nas ações dos investidores através do comportamento dos preços dos ativos e do volume de negociação; (ii) Discretionary-based Disclosure, que considera os incentivos dados a gerentes e/ou às empresas para divulgar informações conhecidas por eles; e (iii) Efficiency-based Disclosure, que examina quais arranjos de divulgação são preferidos na ausência de conhecimento prévio da informação, estando a escolha por divulgar incondicionada.

Portanto, conforme discutido na seção anterior, maior conformidade leva a níveis mais altos de divulgação de informações, sejam elas privadas ou não privadas, boas ou más notícias (Verrecchia, 2001). Por conseguinte, as empresas que exercem discricionariedade positiva, ao divulgar informações que fornecem informações privadas e que revelam o julgamento e as expectativas dos gestores acerca dos objetivos de longo prazo, em particular no que diz respeito aos ativos intangíveis, se beneficiam de um maior valor de mercado (André et al., 2017).

Nesse sentido, Amaral et al. (2014), com base nas informações de mercado, indicam que, em média, o valor das empresas cotadas nas principais bolsas de valores do mundo oscila entre duas e nove vezes o valor contábil de cada uma delas, atribuindo o crescimento dessa diferença nos últimos anos, particularmente, à relevância assumida, na composição patrimonial das empresas, pelos ativos intangíveis em relação aos chamados ativos tangíveis.

Sob a perspectiva dos efeitos dos intangíveis, Nagaraja e Vinay (2016) investigaram empiricamente a relação entre ativos intangíveis, políticas financeiras e desempenho financeiro 
com o valor da empresa no mercado indiano. Dentre os resultados reportados pelos autores, apesar de os ativos intangíveis não exercerem influência significativa nas políticas financeiras, estes influenciam positiva e significativamente no desempenho financeiro, medido pelo ROA, assim como no valor da empresa. A limitação das demonstrações contábeis na mensuração e divulgação de ativos intangíveis é a causa de diferença significativa entre o valor patrimonial do valor contábil e o valor de mercado.

Complementarmente, Andonova e Ruíz-Pava (2016) analisaram os fatores que estão relacionados ao desempenho das empresas colombianas no período de 1995 a 2012 e evidenciaram que as estimativas permitiram explorar o papel da rentabilidade do intangível, revelando que os ativos intangíveis desempenham um papel de destaque entre os fatores específicos de desempenho da empresa, além de confirmarem a resiliência de ativos intangíveis como propulsores de vantagem competitiva em mercados emergentes.

Dessa forma, os resultados encontrados mostram que os ativos intangíveis explicam uma parcela não negligenciável da variação total do desempenho da empresa, confirmando a capacidade das companhias de agregar valor usando os ativos intangíveis como alavanca competitiva (Andonova \& Ruíz-Pava, 2016).

Além disso, uma análise das companhias listadas no IBrX 100, realizada por Medrado et al. (2016), evidenciou a associação positiva e estatisticamente significante entre o nível de intangibilidade dos ativos e o grau de valorização das ações, demonstrando que maiores investimentos em ativos intangíveis podem proporcionar uma valorização no preço de mercado da empresa.

Diante do disposto anteriormente, tendo em vista que o nível de investimentos em ativos intangíveis pode gerar benefícios aos stakeholders, espera-se que as companhias brasileiras que negociam suas ações na B3 possam também estar incorrendo em maiores valores de mercado em decorrência do seu nível de divulgação de investimentos em ativos intangíveis, conforme proposto na hipótese de pesquisa $\mathrm{H}_{1}$ :

H1: Há relação positiva entre o nível de intangilidade das companhias abertas listadas na B3 e o valor mercado.

\section{SELEÇÃO DA AMOSTRA E DESIGN DA PESQUISA}

\subsection{Seleção da amostra}

A amostra do presente estudo compreende companhias abertas brasileiras com ações negociada na B3, com dados disponíveis ao longo do período de 2010 a 2018, coletados por meio da base de dados Thomson Reuters Eikon. Em decorrência da adoção obrigatória do International Financial Reporting Standard no Brasil ter se iniciado em 2010, propiciando um aumento na qualidade das informações contábeis, foi considerado esse período (Pelucio-Grecco, Geron, \& Grecco, 2014), tendo em vista que as mudanças provenientes da adoção podem afetar os dados econômico-financeiros que são de interesse nessa investigação.

Além disso, a vigência, a partir de 2008, da Lei $\mathrm{n}^{\circ} 11.638 / 07$, bem como do pronunciamento CPC 04, passou a definir o tratamento contábil dos ativos intangíveis, incluindo a uniformização quanto ao reconhecimento, mensuração e evidenciação, aspectos estes que não eram abrangidos especificamente em outros pronunciamentos (Medrado et al., 2016).

A amostra é composta por todas as companhias abertas listadas na B3, correspondendo a 412 companhias listadas. Entretanto, foram excluídas 110 companhias financeiras, por possuírem particularidades em suas estruturas patrimonial e operacional, podendo distorcer a definição de algumas variáveis, enviesando os resultados estimados (Costa et al., 2018). Além das companhias financeiras, foram excluídas também as que não possuíam todas as informações econômicofinanceiras necessárias à realização das análises, o que corresponde a um quantitativo de 144 
empresas. Desse modo, 158 companhias compõem a amostra, totalizando 1057 observações, conforme evidenciado na Tabela 1.

Tabela 1

\section{Procedimento de seleção da amostra}

\begin{tabular}{lc}
\hline & Companhias \\
\hline Total de empresas de capital aberto brasileiras & 412 \\
(-) Companhias financeiras & $(110)$ \\
(-) Sem dados para o período analisado & $(144)$ \\
Amostra Final & 158 \\
\hline
\end{tabular}

Visando evitar viés de sobrevivência, mesmo as companhias que não apresentaram dados ao longo de todos os anos da janela temporal analisada foram incluídas na amostra. Sendo assim, as análises foram realizadas a partir de dados em painel desbalanceado. Adicionalmente, como forma de mitigar o efeito de outliers na amostra, foi aplicada a winsorização dos dados quantitativos ao nível de 1\%, conforme preconizado por Hastings, Mosteller, Turkey e Winsor (1947).

\subsection{Design da pesquisa}

Com intuito de investigar se existe associação entre o nível de intangibilidade e o valor de mercado das companhias abertas com ações negociadas na B3, estimou-se um modelo de regressão múltipla com efeitos fixos robustos e com dados dispostos em painel. A decisão pela adequabilidade do método decorreu da realização dos testes de Breusch-Pagan e de Hausman, resultando na utilização do modelo por efeitos fixos

Nesse sentido, a fim de testar a hipótese de pesquisa H1, foi estimado o seguinte modelo econométrico:

$$
\begin{aligned}
\text { MTB }_{\mathrm{i}, \mathrm{t}}=\beta_{0} & +\beta_{1} \text { Intang }_{\mathrm{i}, \mathrm{t}}+\beta_{2} \text { ROE }_{\mathrm{i}, \mathrm{t}}+\beta_{3} \text { Alav }_{\mathrm{i}, \mathrm{t}}+\beta_{4} \text { EBITDA }_{\mathrm{i}, \mathrm{t}}+\beta_{5} \text { Tamanho }_{i, t}+\beta_{6} \text { Ano }_{\mathrm{i}, \mathrm{t}} \\
& +\beta_{7} \text { Setor }_{\mathrm{i}, \mathrm{t}}+\varepsilon_{i, \mathrm{t}}
\end{aligned}
$$

Na Tabela 2, encontram-se listadas as variáveis incluídas no modelo econométrico, a forma como foram calculadas, bem como os estudos prévios que investigaram fatores que podem estar relacionados ao valor da empresa que subsidiaram a inclusão dessas variáveis.

Tabela 2

\begin{tabular}{|c|c|c|c|}
\hline Abreviação & Variável & Descrição & Estudos Anteriores \\
\hline$M T B$ & $\begin{array}{l}\text { Oportunidade de } \\
\text { Crescimento }\end{array}$ & $\begin{array}{l}\text { Razão entre o valor de mercado da } \\
\text { empresa e o valor patrimonial da } \\
\text { empresa. }\end{array}$ & $\begin{array}{l}\text { Medrado et al. (2016); Nagaraja e } \\
\text { Vinay (2016); André et al. (2017); } \\
\text { Carvalho, Maia, Louzada e } \\
\text { Gonçalves (2017). }\end{array}$ \\
\hline Intangibilidade & $\begin{array}{l}\text { Nível de } \\
\text { Intangibilidade }\end{array}$ & $\begin{array}{l}\text { Valor total dos ativos intangíveis, } \\
\text { ponderado pelo total de ativos. }\end{array}$ & $\begin{array}{l}\text { Andonova e Ruíz-Pava (2016); } \\
\text { Nagaraja e Vinay (2016); } \\
\text { Medrado et al. }(2016) .\end{array}$ \\
\hline$R O E$ & $\begin{array}{l}\text { Retorno sobre o } \\
\text { Patrimônio } \\
\text { Líquido }\end{array}$ & $\begin{array}{l}\text { Razão entre o lucro líquido e o } \\
\text { patrimônio líquido. }\end{array}$ & $\begin{array}{l}\text { Andonova e Ruíz-Pava (2016); } \\
\text { Medrado et al. (2016); Akgun, } \\
\text { Samiloglu e Oztop (2018). }\end{array}$ \\
\hline Alavancagem & $\begin{array}{l}\text { Alavancagem } \\
\text { Financeira }\end{array}$ & $\begin{array}{l}\text { Razão entre o total de dívidas } \\
\text { financeiras e o ativo total. }\end{array}$ & $\begin{array}{l}\text { (2016); Carvalho et al. (2017); Li, } \\
\text { Gong, Zhang e Koh (2018); } \\
\text { Battisti, Bollani, Miglietta e Salvi } \\
\text { (2020). }\end{array}$ \\
\hline
\end{tabular}

Descrição das variáveis 
EBITDA EBTIDA Valor do lucro antes de juros, ponderado pelo total de ativos.

Tamanho Tamanho da Firma
Logaritmo natural do ativo total.
Medrado et al. (2016); Postula e Chmielewski (2019).

Kayo et al. (2009); Sousa, Silva, Ribeiro e Weffort (2014); André et al. (2017); Li et al. (2018).

A variável market-to-book (MTB) foi elencada como proxy para valor da empresa e assume o papel de variável dependente do modelo. A escolha da oportunidade de crescimento como proxy está fundamentada na perspectiva de que esse índice representa o quanto uma empresa é valorizada (MTB > 1) ou desvalorizada (MTB < 1) pelo mercado em relação ao seu valor contábil (Carvalho et al., 2017). Ligando a explicação com a teoria da divulgação, entende-se que os maiores níveis de divulgação por parte das companhias em ativos intangíveis podem gerar resultados positivos no valor da empresa.

Em consonância com estudos anteriores, a variável independente interesse da investigação é a Intangibilidade, que reporta a proporção de ativos intangíveis em relação ao total de ativos apresentados no balanço patrimonial das empresas brasileiras objetos da análise (Andonova \& Ruíz-Pava, 2016; Medrado et al., 2016; Nagaraja \& Vinay, 2016).

A utilização dessa proxy pauta-se na prerrogativa de que os ativos intangíveis podem representar uma parte crítica dos relatórios corporativos e, cada vez mais, são projetados para promover um desempenho sustentável a longo prazo, que beneficia todos os interessados (Madden, 2017). Além disso, a maior participação dos ativos intangíveis na estrutura patrimonial, em detrimento de outros ativos, pode aumentar a perspectiva de geração de lucros anormais (Medrado et al., 2016).

Em relação às variáveis de controle incluídas no modelo, o ROE é um indicador financeiro que reflete a capacidade da empresa em agregar valor a ela mesma, utilizando os seus próprios recursos (Medrado et al., 2016). A inclusão dessa variável no modelo justifica-se por ser uma medida comumente utilizada para medir o desempenho contábil, além de ser um bom indicador da lucratividade de uma empresa, evidenciando a eficácia na utilização de seus recursos próprios para gerar resultado (Lys, Naughton, \& Wang, 2015; Najah \& Jarboui, 2013). Dessa forma, esperase que maiores índices de retorno sobre o capital próprio apresentem associação positiva com o valor de mercado.

No tocante à variável Alavancagem, esta representa o grau de alavancagem financeira das empresas e traduz a capacidade de, a partir da utilização de recursos de terceiros em sua estrutura de capital, agregar valor à empresa (Medrado et al., 2016). Além disso, a alavancagem pode ser configurada como uma métrica para o risco da empresa (Lys et al., 2015; Plumlee, Brown, Hayes, $\&$ Marshall, 2015). Nesse sentido, baseado na premissa de risco e retorno e na possibilidade de a estrutura de capital apresentar forte relação e impacto positivo sobre o valor da firma (Silva \& Silva, 2017), é esperada relação positiva entre a alavancagem e o valor de mercado.

A variável de controle EBITDA foi incluída no modelo visto que, conforme ressaltado por Medrado et al. (2016), essa métrica é utilizada, primordialmente, para analisar o desempenho das organizações, por refletir uma proxy da capacidade de geração de caixa operacional, devendo ser percebida de maneira positiva pelo mercado.

Por fim, o logaritmo natural do ativo foi incluído como proxy para tamanho (Tamanho), sendo incorporado ao modelo objetivando capturar os efeitos do porte da empresa no valor de mercado das empresas, tendo em vista que essa é uma variável que pode impactar no valor da firma e partindo do pressuposto de que as companhias maiores tendem a apresentar também um valor de mercado maior (Li et al., 2018; Sousa et al., 2014).

Complementarmente, foram incluídos no modelo controles para o setor de atuação das companhias e o ano, tendo em vista que a relação analisada pode variar em função do segmento de atuação da empresa (Iatridis, 2013; Sousa et al., 2014). Além disso, em relação ao ano, entende- 
se que a situação financeira das empresas pode ser influenciada por questões macroeconômicas, tornando-se necessário controlar os efeitos dessas possíveis variações (Sousa et al., 2014).

\section{RESULTADOS}

\subsection{Análise descritiva}

$\mathrm{Na}$ análise descritiva, observa-se que o índice médio de oportunidade de crescimento $(M T B)$ - assumida como proxy para valor de mercado - das companhias listadas na B3 é de 2,6. Nesse sentido, é possível afirmar que, em média, o valor de mercado das empresas que negociam suas ações na B3 é, aproximadamente, 2,6 vezes maior que o valor reportado nas demonstrações contábeis. Essa evidência enseja a discussão de que o crescimento dessa discrepância pode estar relacionado com os ativos intangíveis, conforme observado por Amaral et al. (2014).

Em relação à intangibilidade, percebe-se que, em média, $11,56 \%$ do total de ativos é composto por ativos intangíveis. No entanto, é válido ressaltar o desvio-padrão e a distância entre os valores mínimo e máximo, o que pode estar relacionado à complexidade dos ativos intangíveis e à possibilidade de algumas empresas não registrá-los, enquanto que outras possuem quase que a integralidade de seus ativos composta por intangíveis.

Esse aumento na intangibilidade encontra-se em linha com o estudo desenvolvido por Lim et al. (2019), que abordam justamente o fato de que, no mundo contemporâneo dos negócios, uma proporção substancial e crescente de ativos corporativos consiste em ativos intangíveis.

Tabela 3

\section{Estatística descritiva}

\begin{tabular}{lccccc}
\hline Variável & Obs & Média & Desv. Pad. & Mín. & Máx. \\
\hline MTB & 1057 & 2,6021 & 4,4263 & $-14,9139$ & 28,1394 \\
Intangibilidade & 1057 & 0,1156 & 0,1829 & 0,00006 & 0,8433 \\
ROE & 1057 & 0,0642 & 0,3976 & $-2,0645$ & 1,5576 \\
Alavancagem & 1057 & 0,3202 & 0,2402 & 0 & 1,6284 \\
EBITDA & 1057 & 0,0917 & 0,0994 & $-0,4321$ & 0,3388 \\
Tamanho* $^{*}$ & 1057 & 8,1077 & 1,7750 & 2,8496 & 12,6845 \\
\hline
\end{tabular}

Nota. *Variável em logaritmo natural. MTB representa a oportunidade de crescimento da empresa e é calculado pela razão entre o valor de mercado e o valor contábil. Intangibilidade é o nível de intangibilidade da empresa e é calculado pela razão entre o total de ativos intangíveis e o total de ativos. $R O E$ representa o retorno sobre o patrimônio líquido e é calculado pela razão entre o lucro líquido e o patrimônio líquido. Alavancagem é a razão entre dívidas e ativo total. EBITDA corresponde ao valor do lucro antes de juros, impostos, depreciação e amortização, ponderado pelo total de ativos. Tamanho da Firma é o logaritmo natural do ativo total.

No tocante à ROE, verifica-se que, em média, o retorno à utilização do capital próprio das empresas corresponde a $6,42 \%$. Nessa perspectiva, a alavancagem financeira (Alavancagem) demonstra que, em média, a dívida das companhias representa $32 \%$ de seus ativos totais.

No que diz respeito à variável EBITDA, o índice médio do desempenho operacional das companhias corresponde a $9,17 \%$ de seu ativo total - valor próximo, de certa forma, ao evidenciado por Medrado et al. (2016) em análise realizada com as empresas que compõem o IBrX 100.

Por fim, os valores referentes ao tamanho da empresa (Tamanho) foram apresentados pelo seu logaritmo natural.

A Tabela 4 apresenta os resultados do teste de correlação entre as variáveis inseridas no modelo econométrico. Considerando que as variáveis examinadas não apresentaram normalidade, de acordo com o teste de Shapiro-Wilk, foram realizadas correlações de Spearman entre variáveis quantitativas contínuas. 
Tabela 4

Matriz de correlação

\begin{tabular}{|c|c|c|c|c|c|c|c|}
\hline & & 1 & 2 & 3 & 4 & 5 & 6 \\
\hline 1 & $M T B$ & 1 & & & & & \\
\hline 2 & Intangibilidade & 0,2847 & 1 & & & & \\
\hline 3 & $R O E$ & 0,1120 & 0,0698 & 1 & & & \\
\hline 4 & Alavancagem & $\mathbf{0 , 3 3 8 7}$ & 0,1151 & $-0,1246$ & 1 & & \\
\hline 5 & EBITDA & 0,4238 & 0,3960 & 0,1625 & 0,2131 & 1 & \\
\hline 6 & Tamanho & 0,3142 & 0,4015 & $-0,0327$ & 0,3052 & $\mathbf{0 , 8 7 7 9}$ & 1 \\
\hline
\end{tabular}

Nota. Coeficientes em negrito são significativos ao nível de 5\%. MTB representa a oportunidade de crescimento da empresa e é calculado pela razão entre o valor de mercado e o valor contábil. Intangibilidade é o nível de intangibilidade da empresa e é calculado pela razão entre o total de ativos intangíveis e o total de ativos. $R O E$ representa o retorno sobre o patrimônio líquido e é calculado pela razão entre o lucro líquido e o patrimônio líquido. Alavancagem é a razão entre dívidas e ativo total. EBITDA corresponde ao valor do lucro antes de juros, impostos, depreciação e amortização, ponderado pelo total de ativos. Tamanho da Firma é o logaritmo natural do ativo total.

Os resultados da matriz de correlação sinalizam que a intangibilidade possui uma tendência de correlação positiva com o market-to-book, assim como a rentabilidade, o desempenho operacional e o tamanho da empresa apresentam correlação positiva com a proxy de valor de mercado. Em contrapartida, evidencia-se a existência de uma correlação negativa entre a alavancagem das companhias e o market-to-book.

Por meio da Tabela 4, também é possível verificar que a maior correlação entre as variáveis examinadas é de 0,8779 , e, apesar de ser uma correlação forte entre as variáveis Tamanho e EBITDA, os testes de fatores de inflação da variância (VIF) que precederam a estimação do modelo econométrico não reportaram a ocorrência de problemas de multicolinearidade, conforme evidenciado na Tabela 5.

Tabela 5

\section{Variance Inflation Factor}

\begin{tabular}{llc}
\hline \multicolumn{1}{c}{ Variável } & VIF & $\mathbf{1} / \mathbf{V I F}$ \\
Intangibilidade & $\mathbf{1 , 0 4}$ & $\mathbf{0 , 9 5 8 6}$ \\
ROE & $\mathbf{1 , 0 1}$ & $\mathbf{0 , 9 8 7 5}$ \\
Alavancagem & $\mathbf{1 , 0 3}$ & $\mathbf{0 , 9 6 9 3}$ \\
EBITDA & $\mathbf{1 , 0 8}$ & $\mathbf{0 , 9 2 8 5}$ \\
Tamanho & $\mathbf{1 , 1 1}$ & $\mathbf{0 , 8 9 7 4}$ \\
\hline
\end{tabular}

Assim, considera-se que não existem indícios de multicolinearidade, tendo em vista que os valores resultantes estão dentro do limite preconizado para que não haja quebra desse pressuposto (Hair, Anderson, Tatham, \& Black, 1995).

\subsection{Modelo econométrico}

Com o objetivo de investigar se existe associação entre o nível de intangibilidade e o valor de mercado das companhias abertas com ações negociadas na B3, foi utilizado um modelo de regressão por mínimos quadrados ordinários com dados em painel com efeitos fixos, tendo em 
vista a natureza dos dados. Os coeficientes reportados na Tabela 6 podem ser interpretados como os níveis de aumento ou redução do valor de mercado.

Tabela 6

\section{Modelo econométrico}

\begin{tabular}{lc}
\hline Variável Dependente & $M T B$ \\
\hline Intang & $0,956145^{*}$ \\
ROE & $(1,4245)$ \\
Alavancagem & $3,6124^{* * *}$ \\
EBITDA & $(0,8184)$ \\
Tamanho & $3,1717^{*}$ \\
Constante & $3,313)$ \\
Ano & $3,8396^{*}$ \\
Setor & $(3,2885)$ \\
R2 within & $-0,8694$ \\
$R 2$ between & $(0,5921)$ \\
$R 2$ overall & $8,8137^{*}$ \\
Observações & $(4,7205)$ \\
$N^{o}$ de Companhias & Incluído \\
\hline
\end{tabular}

Nota. Erros-padrão reportados entre parênteses. ***, **, * indicam significância ao nível de $1 \%, 5 \%$ e $10 \%$, respectivamente. MTB representa a oportunidade de crescimento da empresa e é calculado pela razão entre o valor de mercado e o valor contábil. Intangibilidade é o nível de intangibilidade da empresa e é calculado pela razão entre o total de ativos intangíveis e o total de ativos. $R O E$ representa o retorno sobre o patrimônio líquido e é calculado pela razão entre o lucro líquido e o patrimônio líquido. Alavancagem é a razão entre dívidas e ativo total. EBITDA corresponde valor do lucro antes de juros, impostos, depreciação e amortização, ponderado pelo total de ativos. Tamanho da Firma é o logaritmo natural do ativo total.

A partir da Tabela 5, verifica-se uma associação positiva e estatisticamente significante entre o nível de intangibilidade das companhias brasileiras e o market-to-book. Essa evidência reporta que, de fato, para amostra objeto de investigação, os ativos intangíveis podem estar agindo como fatores que melhoram a percepção dos investidores acerca da empresa, resultando em maiores valores de mercado. Sendo assim, conclui-se pela não rejeição da hipótese de pesquisa $\mathrm{H}_{1}$, cuja pressuposição é de que há relação positiva entre o nível de intangibilidade das companhias abertas listadas na B3 e o valor mercado.

De forma complementar, também é possível concluir que os resultados reportam à limitação das demonstrações contábeis na mensuração e divulgação de ativos intangíveis, o que implica em diferenças significativas entre o valor patrimonial contábil e o valor de mercado das companhias.

Complementarmente, os achados corroboram com Nagaraja e Vinay (2016) e Andonova e Ruíz-Pava (2016), que encontraram evidências dessa relação positiva dos intangíveis com o valor da empresa também em cenários de mercados emergentes. Nesse contexto - países em desenvolvimento - os ativos intangíveis desempenham, em especial, um papel de destaque entre os fatores específicos de desempenho da empresa, além de agirem como propulsores de vantagem competitiva (Andonova \& Ruíz-Pava, 2016). 
Especificamente no contexto brasileiro, os resultados do presente estudo agregam aos encontrado por Medrado et al. (2016), ao passo que ampliam a visão de que maiores investimentos em ativos intangíveis podem proporcionar uma valorização no preço de mercado da empresa, extrapolando os limites de uma carteira específica (IBrX 100) para as empresas listadas na B3 no geral.

Dessa forma, à luz da teoria do disclosure, infere-se que o fato de as empresas alcançarem uma maior valorização no mercado acionário, mediante a divulgação dos investimentos realizados em ativos intangíveis, reporta à divulgação association-based, já que os efeitos da divulgação geram uma mudança agregada nas ações dos investidores, modificando o comportamento dos preços dos ativos e do volume de negociação (Verrecchia, 2001).

Destarte, ao fornecerem ao mercado informações das expectativas dos gestores acerca dos objetivos de longo prazo, em particular no que diz respeito aos ativos intangíveis, se beneficiam de um maior valor de mercado - considerando que os intangíveis atuam como mecanismos de manutenibilidade da empresa a longo prazo (André et al., 2017).

Em relação ao ROE, este apresentou uma associação positiva com o valor do mercado, reportando que empresas que atingem melhor desempenho financeiro tomando como estrutura a utilização de capital próprio apresentam maiores oportunidades, crescimento e, portanto, maior valor de mercado. Dessa forma, infere-se que o ROE é percebido como um agregador de valor pelos investidores, indicando ao mercado a lucratividade da empresa, bem como evidenciando a eficácia na utilização de seus recursos próprios para gerar resultado (Lys et al., 2015; Medrado et al., 2016; Najah \& Jarboui, 2013).

A variável Alavancagem, que remete à utilização de capital de terceiros, apresentou uma relação positiva e estatisticamente significativa com o valor de mercado. Essa relação, corroborando com Medrado et al. (2016), indica que há evidências de que o mercado precifica de maneira positiva, até certo nível, o retorno esperado em decorrência do risco assumido por empresas alavancadas. Nesse sentido, a alavancagem pode estar relacionada à criação de valor para os acionistas (Pandya, 2016).

No tocante à variável EBITDA, a associação positiva com o market-to-book evidencia que o parâmetro é percebido de maneira positiva pelo mercado, tendo em vista que evidencia o desempenho das organizações, e reflete a capacidade de geração de caixa operacional (Medrado et al., 2016).

Esse resultado segue a mesma linha de Medrado et al. (2016) ao passo que também evidenciou, conforme os autores, que os investidores valorizam as empresas capazes de gerar caixa operacional, considerando que isso reflete também a capacidade da empresa em honrar as suas obrigações contratuais, gerar resultados e distribuir dividendos.

Por fim, a variável relativa ao tamanho (Tamanho) não apresentou significância estatística. Portanto, não é possível inferir que esse fator econômico-financeiro, que representa o porte da empresa por meio do logaritmo natural do total de ativos, tenha relação com o valor de mercado das empresas no caso das companhias abertas brasileiras.

\section{CONSIDERAÇÕES FINAIS}

Diante da crescente proporção de investimento nos ativos intangíveis, em detrimento de ativos tangíveis, e a gradativa discussão acadêmica acerca das particularidades dos elementos que compõem essa classe, o presente estudo se propôs a investigar se existe associação entre o nível de intangibilidade e o valor de mercado das companhias abertas com ações negociadas na B3.

As análises foram realizadas com 158 empresas, com dados disponíveis em referência ao período de 2010 a 2018. Em relação à análise econométrica, foi utilizado o modelo de regressão por mínimos quadrados ordinários com dados em painel com efeitos fixos.

Mediante os resultados obtidos, foi possível identificar que, de fato, o nível de intangibilidade das companhias apresenta uma relação positiva e estatisticamente significante com 
o valor de mercado da empresa. Esse achado levou à não rejeição da hipótese de pesquisa $\mathrm{H}_{1}$, que pressupunha a existência de relação positiva entre o nível de intangibilidade das companhias abertas listadas na B3 e o valor de mercado atribuído.

Identificou-se ainda que a rentabilidade sobre o capital próprio, o EBITDA e Tamanho da companhia são fatores que se relacionam de maneira positiva com o valor da empresa. Dessa forma há evidências de que as companhias com maior rentabilidade para os acionistas, melhor desempenho operacional e maior porte apresentam maiores valores de mercado.

Levando-se em consideração a amostra diversificada, o período e a técnica utilizada, esses achados trazem uma nova perspectiva para os estudos na área, contribuindo com os trabalhos anteriores de maneira a satisfazer os hiatos existentes, principalmente no que diz respeito à relação que a apresentação de ativos intangíveis tem com o valor das companhias abertas brasileiras.

Outrossim, os resultados apontam para consideráveis implicações para as empresas, gestores e acionistas. Na medida em que se compreende a influência positiva exercida pelo nível de investimento em ativos intangíveis no valor da empresa, pode-se inferir que benefícios fluirão dessa relação, já que o aumento no preço das ações pode implicar em ganhos para os stakeholders.

Considera-se, portanto, que os resultados do presente estudo podem ser utilizados como base para outros trabalhos, tendo em vista que é uma área com muitas lacunas a serem discutidas empiricamente, tanto no âmbito nacional quanto no âmbito internacional. Além disso, o passar dos anos traz novas exigências que podem fazer com que as relações aqui apresentadas sejam modificadas.

Ressalta-se também a possibilidade de replicar o estudo sob outras métricas e métodos para testar se os resultados convergem, já que os trabalhos disponíveis sobre o tema utilizam variáveis e metodologias distintas, inclusive em relação à proxy representativa do nível de investimento em ativos intangíveis.

No que se refere à teoria da divulgação, os achados permitem associar o nível de divulgação dos investimentos e o valor de mercado, uma vez que os resultados sinalizam que os efeitos da divulgação geram uma mudança agregada nas ações dos investidores. Ainda, trata-se a teoria analisada como desafios e oportunidades para novas pesquisas e uma limitação para o estudo presente, pois poucos estudos abordaram a mesma, o que limitou mas não invalidou as discussões no presente estudo. Por fim, sugere-se que pesquisas futuras busquem identificar o impacto dos intangíveis em outros aspectos contábeis, como a criação de valor, mensuração e regulação, ou até mesmo comparando os resultados entre mercados diferentes.

\section{REFERÊNCIAS}

Akgun, A. I., Samiloglu, F., \& Oztop, A. O. (2018). The Impact of Profitability on Market Value Added: Evidence from Turkish Informatics and Technology Firms. International Journal of Finance and Economics Issues, 8(4), 105-112.

Amaral, H. F., Iquiapaza, R. A., Correia, L. F., Amaral, G. H. O., \& Vieira, M. V. (2014). Avaliação de ativos intangíveis: modelos alternativos para determinação do valor de patentes. Gestão, Finanças e Contabilidade, 4(1), 123-143.

André, P., Filip, A., \& Paugam, L. (2017). Examining the Patterns of Goodwill Impairments in Europe and the US. Accounting in Europe, 13(3), 329-352.

Andonova, V., \& Ruíz-Pava, G. (2016). The role of industry factors and intangible assets in company performance in Colombia. Journal of Business Research, 69(10), 4377-4384.

Arrighetti, A., Landini, F., \& Lasagni, A. (2014). Intangible assets and firm heterogeneity: Evidence from Italy. Research Policy, 43, 202-213. 
Battisti, E., Bollani, L., Miglietta, N., \& Salvi, A. (2020). The impact of leverage on the cost of capital and market value: Evidence from Sharī'ah-compliant firms. Management Research Review, 43(3).

Bryan, D., Rafferty, M., \& Wigan, D. Capital unchained: finance, intangible assets and the double life of capital in the offshore world. Review of International Political Economy, 24(1), 56-86.

Carvalho, F. P., Maia, V. M., Louzada, L. C., \& Gonçalves, M. A. (2017). Desempenho setorial de empresas brasileiras: um estudo sob a ótica do ROE, Q de Tobin e market-to-book. Gestão, Finanças e Contabilidade, 7(1), 149-163.

Dehning, B., Pfeiffer, G. M., \& Richardson, V. J. (2006). Analysts' forecasts and investments in information technology. International Journal of Accounting Information Systems, 7(3), 238250 .

Gazzoni, G. G. Jr., Simões, J. J. F., Brandão, M. M., \& de Souza, A. A. (2019). Os efeitos dos intangíveis nas previsões dos analistas financeiros. Revista Catarinense da Ciência Contábil, 18, 1-18.

Gu, F., \& Wang, W. (2005). Intangible Assets, Information Complexity, and Analysts' Earnings Forecasts. Journal of Business Finance \& Accounting, 32(9-10), 1673-1702.

Hair, J. F. Jr., Anderson, R. E., Tatham, R. L., \& Black, W. C. (1995). Multivariate Data Analysis (3rd ed.). New York: Macmillan.

Hastings J., C., Mosteller, F., Tukey, J. W., \& Winsor, C. P. (1947). Low moments for small samples: a comparative study of order statistics. The Annals of Mathematical Statistics, 18(3), 413-426.

Higgins, H. (2013). Can securities analysts forecast intangible firms' earnings? International Journal of Forecasting, 29(1), 155-174.

Iatridis, G. E. (2013). Environmental disclosure quality: evidence on environmental performance, corporate governance and value relevance. Emerging Markets Review, 14, 55-75.

Kayo, K. E., Patrocínio, M. R., \& Martin, D. M. L. (2009). Intangibilidade e criação de valor em aquisições: o papel moderador do endividamento. Revista de Administração, 44(1), 59-69.

Koller, T., Goedhart, M., Wessels, D. (2005). Valuation: measuring and managing the value of companies. New Jersey: John Wiley \& Sons.

Labidi, M., \& Jean François, G. (2019). Does increased disclosure of intangible assets enhance liquidity around new equity offerings? Research in International Business and Finance, 48(C), 426-437.

Li, Y., Gong, M., Zhang, X., \& Koh, L. (2018). The impacto of environmental, social, and governance disclosure on firm value: the role of CEO power. The British Accounting Review, $50,60-75$. 
Lim, S. C., Macias, A. J., \& Moeller, T. (2019) Identifiable intangible assets and capital structure, Working Paper. Available at SSRN 2514551.

Loop, D., Scheffer, G. V., Lipfert, S. (2004). Patent valuation at IP Bewertungs AG. World Intelectual Property Organization, 2004.

Lys, T., Naughton, J. P., \& Wang, C. (2015). Signaling through corporate accountability reporting. Journal of Accounting and Economics, 60, 56-72.

Madden, J. (2017). The Purpose of the Firm, Valuation, and the Management of Intangibles. Journal of Applied Corporate Finance, 29(2), 76-87.

Mazzi, F., André, P., Dionysiou., D., \& Tsalavoutas, I. (2017). Compliance with Goodwill-Related Mandatory Disclosure Requirements and the Cost of Equity Capital. Accounting and Business Research, 47(3), 268-312.

Medrado, F., Cella, G., Pereira, J. V., \& Dantas, J. A. (2016). Relação entre o nível de intangibilidade dos ativos e o valor de mercado das empresas. Revista Contabilidade e Organizações, 28, 32-44.

Moura, G., Barbosa, S., Schio, N., \& Mazzioni, S. (2020). Ativos intangíveis influenciam no desempenho financeiro e no valor de mercado de companhias abertas familiares?. Revista Catarinense da Ciência Contábil, 19, e2815.

Najah, A., \& Jarboui, A. (2013). The social disclosure impact on corporate performance: case of big french companies. International Journal of Management and Business Research, 3(4), 337351.

Nagaraja, N., \& Vinay, N. (2016). The Effect of Intangible Assets on the Firm Value. International Journal of Engineering and Management Research, 6(1), 307-315

Nichita, M. E. (2019). Intangible assets-insights from a literature review. Journal of Accounting and Management Information Systems, 18(2), 224-261.

Pandya, B. (2016). Impact of financial leverage on market value added: empirical evidence from India. Journal of Entrepreneurship and Economics, 4(2), 40-58.

Pelucio-Grecco, M. C., Geron, C. M. S., \& Grecco, G. B. (2014). The effect of IFRS on earnings management in Brazilian non-financial public companies. Emerging Markets Review, 21, 4266.

Plumlee, M., Brown, D., Hayes, R. M., \& Marshall, R. S. (2015). Voluntary environmental disclosure quality and firm value: further evidence. Journal of Accounting and Public Policy, 34(4), 336-361.

Postula, M., \& Chmielewski, W. (2019). The impact of intangible assets and R\&D expenditure on the market capitalization and EBITDA of selected ICT sector enterprises in the European Union. International Journal of Economics and Finance, 11(8), 117-128.

Shalev, R. (2009). The information content of business combination disclosure level. The Accounting Review, 84(1), 239-270. 
Silva, J. P., \& Silva, D. C. (2017). Análise da relação entre estrutura de capital, crescimento, lucratividade e valor de mercado das companhias brasileiras de capital aberto. Revista Mineira de Contabilidade, 18(1), 16-25

Silveira, S. K. R., Schnorrenberger, D., Gasparetto, V., \& Lunkes, R. J. (2017). Abordagens de avaliação de ativos intangíveis: uma revisão da literatura. Revista Catarinense da Ciência Contábil, 16(47).

Sousa, C. B., Silva, A. F., Ribeiro, M. S., \& Weffort, E. F. J. (2014). Valor de mercado e disclosure voluntário: estudo empírico em companhias listadas na BM\&FBovespa. Revista Ambiente Contábil, 6(2), 94-115.

Verrecchia, R. E. (1983). Discretionary disclosure. Journal of accounting and economics, 5, 179194.

Verrecchia, R. E. (2001). Essays on disclosure. Journal of Accountin and Economics, 32, 97-180. 